\title{
Representación de la mujer y estándares de belleza en la publicidad de pro- ductos de cuidado personal: un análisis de contenido
}

\author{
Alejandra Acuña González* \\ Tecnológico de Monterrey, Campus Monterrey
}

\section{RESUMEN}

A través del análisis de 740 anuncios de productos de belleza y cuidado personal presentes en revistas de estilo de vida/moda se obtuvieron resultados sobre la representación de la mujer. La industria publicitaria ha sido señalada por promover estándares de belleza inalcanzables, los cuales se vuelven el común y enseñan como ver e interpretar el propio cuerpo y el de los demás. Se consideraron las características físicas y la presentación del personaje en el anuncio. Los resultados indican poco cambio en la representación de la mujer y un énfasis en la cuestión de juventud.

Palabras clave: publicidad, representación, género, belleza

\begin{abstract}
Through the analysis of 740 beauty and personal care product advertisements present in lifestyle/fashion magazines results about women representation were obtained. The advertising industry has been blamed for promoting unattainable beauty standards, which become common and teach how to look at and interpret bodies. The physical characteristics and the presentation of the character were taken into account. The results point out little change in women's representation and a focus on youth.
\end{abstract}

Keywords: advertising, representation, gender, beauty

\footnotetext{
*Doctora en Estudios Humanísticos con especialidad en Comunicación y Estudios Culturales del Tecnológico de Monterrey, Campus Monterrey. Correo electrónico: a.acunna@gmail.com.
} 


\section{INTRODUCCIÓN}

Los medios de comunicación y en general las sociedades se encargan de establecer y reproducir construcciones conceptuales para la vida diaria, la belleza y la imagen personal se encuentra entre ellos. Estas concepciones de la belleza ejercen una influencia sobre la percepción de los cuerpos ideales y en consecuencia la percepción del propio cuerpo. La problemática consiste en tener un concepto arraigado de belleza y perfección, que no se cuestiona por aparentar ser un concepto natural y no uno construido.

El Centro Nacional de Equidad de Género y Salud Reproductiva en su Guía de Trastornos Alimenticios (2004) menciona sobre las exigencias sociales de ser mujer "eternamente adolescentes y al mismo tiempo madres; físicamente jóvenes, pero con la experiencia de la madurez, tener un cuerpo esbelto, hermoso y atractivo sin dejar de ser inteligentes, hábiles y astutas...”.

Diversos estudios sobre desórdenes alimenticios han identificado consistentemente el énfasis sociocultural de esbeltez como causa principal en el desarrollo de estas enfermedades (Park, 2005). Anteriormente se hablaba del poder de los medios sobre las audiencias sin embargo estudios más recientes mencionan que los efectos son limitados, ya que el receptor juega un papel importante en la aceptación, negociación o rechazo de los mensajes.

\section{Industria publicitaria}

Virtualmente cada imagen de las celebridades en revistas ha sido modificada por un programa profesional, lo que implica no solo un engaño, sino una enseñanza perceptual del cuerpo propio. Las imágenes que son bombardeadas, se vuelven el común y enseñan como ver e interpretar el propio cuerpo y el de los demás. Menciona Bordo (2004) que esas creaciones digitales, ciborgs visuales, enseñan que esperar de un cuerpo de carne y hueso, moldeando la percepción de lo que es un defecto y lo que es normal.

La publicidad ha sido señalada por sostener o incluso crear el estándar demacrado de la belleza, al cual las niñas desde temprana edad se les enseñara a juzgar sus propios cuerpos (Freedman, 1984; Nichter and Nichter 1991; Solomon, 1992, en Stephens, Hill, y Hanson, 1994). Al no presentar un diverso rango de tipos de cuerpo, las revistas de moda promueven la delgadez como lo deseable y la norma prevalente entre las mujeres. La idea de cualquier desviación de este ideal delgado es implícitamente anormal (Kilbourne, 2000).

La inseguridad de cuerpo puede ser exportada, importada y mercantilizada a través del mundo, justo como cualquier otra comodidad rentable (Bordo, 2004). Ésta inseguridad va de la mano con el consumo, es común encontrar en la publicidad mensajes que señalan las faltas y problemas, quizá al- 
guno que no se había considerado antes, y ahí mismo presentan un producto para resolverlo.

La publicidad se presenta, de acuerdo a Qualter (1994), como parte de los "mecanismos de reducción de ansiedad" de la sociedad, realizando la misma función que mitos e ideologías. Muchos productos y servicios anunciados ofrecen mejorar la tensión de la vida moderna. Entonces la publicidad tiene un doble papel, por un lado, fomenta una serie de inseguridades y por otro, promociona productos que darán respuesta a esas inseguridades. El mensaje implícito en el anuncio es que la infelicidad individual y el malestar social pueden mejorarse por medio de más adquisiciones.

En cuanto a características físicas, Cáceres Zapatero y Díaz Soloaga (2008) encontraron en una muestra de anuncios en revistas españolas que nueve de cada 10 mujeres eran de raza caucásica (blanca), pocas negras, asiáticas o cobrizas. Un 9.5\% presentaban aspecto aniñado, emulando un tipo de Lolita. En otros términos, todos los productos se caracterizaban por mostrar una mujer con el perfil estético de mujer blanca, joven y delgada. La exhibición del cuerpo se daba primordialmente por el cuerpo entero, luego busto y luego solo rostro. Solo una de cada cinco mujeres aparece con el cuerpo desnudo o semi-desnudo en ese estudio. Concluyen que la edad y la imperfección se presen- tan como un mal evitable y el consumo como la solución a un ideal inalcanzable y frustrante, conduce al consumo y beneficia al sistema productivo y a los anunciantes, pero a nivel individual produce insatisfacción. Por otra parte, en las revistas británicas estudiadas por Plakoyiannaki y Zotos (2008) se promovía un ideal de feminidad provocadora, esto es de acuerdo a Cortese (2008) el ideal de una mujer joven, seductora con deseo sexual y atractivo físico.

Muise y Desmarais (2010) mencionan que las mujeres mayores no se representan y el movimiento anti-edad se encarga de que el proceso natural que se experimenta con la edad sea uno rechazado socialmente y que debe ser remediado.

Los anuncios tratan de atraer la atención, crear un deseo, estimular una acción que lleve a la compra. En general, persuadir, motivar y actuar. El modelo psico-cultural de Berger (2011) considera que al exponer el inconsciente a la publicidad resulta en el comportamiento cultural. Viendo a grandes rasgos el comportamiento colectivo, parece ser que los anuncios publicitarios son poderosos.

La publicidad se defiende utilizando una argumentación post hoc, ergo propter hoc, solo porque $\mathrm{X}$ pasa después de $\mathrm{Y}$ no significa que fue causado por $\mathrm{X}$. El autor menciona que no se debe simplificar la publicidad como algo mecánico e inmediato, pero tampoco 
debe subestimar su influencia en los individuos, sociedad y cultura.

Con base en lo anterior se puede decir que las concepciones de la belleza, especialmente de las mujeres, que se presentan en los medios y en las sociedades ejercen una influencia sobre la percepción de los cuerpos ideales y en consecuencia la percepción del propio cuerpo. El hacer un análisis de la representación de la mujer en los anuncios publicitarios de productos belleza y cuidado personal encontrados en revistas de estilo de vida y moda, permite hacer una comparación entre las imágenes que vemos día a día y los estereotipos y estándares históricos que se presentan de la mujer. La problemática consiste en tener un concepto arraigado de belleza y perfección, que no se cuestiona por aparentar ser un concepto natural y no uno construido. La importancia de abordarlo desde una perspectiva de estudios culturales radica en la creación de significados y los discursos reguladores de los medios que moldean la vida en sociedad. El objetivo principal de la investigación fue identificar las características físicas de la mujer en la publicidad de productos de belleza y cuidado personal.

El estudio busca aportar elementos para reflexionar sobre la publicidad como industria cultural, como ente creador y diseminador del imaginario de perfección presentado a las mujeres en estos anuncios.

\section{METODOLOGÍA}

Se utilizó la técnica cuantitativa de análisis de contenido para estudiar sistemáticamente las variables asignadas. Se tomó como unidad de análisis todos los anuncios publicitarios que presentaran una extensión igual o superior a una página, en donde se promovieran productos de cuidado personal, moda, deporte y medicinas o suplementos alimenticios encaminados al segmento de la mujer.

Se decidió incluir aquellos anuncios que aparecieron publicados en más de una ocasión, esto es, al considerar la propuesta de Odekerken-Schröder, De Wulf y Hofstee (2002), quienes sostienen que este tipo de situaciones resultan apropiadas ya que reflejan la verdadera exposición de los lectores a los anuncios.

Se determinó enfocar la atención en los anuncios publicitarios impresos en revistas, ya que en éstos es posible observar sistemáticamente las representaciones femeninas (Goffman, 1987).

$\mathrm{El}$ autor sostiene que, debido al espacio tan reducido para apelar a la audiencia, el creativo se ve en la necesidad de incluir símbolos simples, pero fuertes como es el caso de los estereotipos de género.

Asimismo, se remarca como es que el texto debe ser conciso y reflejar lo que la marca quiere transmitir en una sola vista o en un tiempo corto. 
La selección de las publicaciones a considerar para el universo del estudio tomó en cuenta la variedad del mercado mexicano en revistas de estilo de vida/moda para mujeres. Por su alcance y popularidad, se eligieron las editoriales Grupo Expansión, Editorial Televisa y Condé Nas Digital. A partir de esos grupos se seleccionaron las publicaciones enfocadas a estilo de vida y moda: Elle, InStyle, Cosmopolitan, V anidades, Glamour y Vogue. El rango de edad de las lectoras es de 18 a 55 años y el nivel socioeconómico predominante es el medio alto y alto. Se seleccionaron cuatro meses del periodo diciembre 2014-diciembre 2015, resultando elegidos febrero, abril, junio y octubre.

\section{RESULTADOS}

Aunque se menciona que el ideal de belleza no es un concepto estático sino uno que se modifica y adapta a las ideas, personalidades e incluso marcas y productos del momento, existen ciertas características que corresponden al ideal de belleza por su prevalencia en los medios. El estereotipo de belleza en los medios puede convertirse en inspiración de los espectadores, como mencionan algunos autores, el leer revistas de belleza se relaciona con la internalización de los ideales sociales y la auto-cosificación.

Se estudió un total de 740 anuncios publicitarios, más de la mitad de los productos anunciados en este tipo de publicaciones ha- cían referencia a la moda $(53.7 \%)$, en esta categoría se incluyeron artículos como ropa, zapatos y accesorios. En segundo lugar, se destacan también los anuncios relacionados con el cuidado personal (36.1\%). Esta variable incluía anuncios relacionados con artículos como champú, desodorantes, higiene femenina, cremas y perfumes.

Se buscó identificar el grupo de edad al que pertenecía la mujer principal presente en los anuncios, se trata en este caso, de una variable que representa un estado más subjetivo de análisis, de manera que en algunas ocasiones no podía distinguirse y calificarse con certeza, de ahí la necesidad de contar con un buen instrumento que garantizara la fiabilidad de los resultados. Una vez superada esta situación se encontró que el grupo de edad de 26 a 35 años representaba casi la mitad de los casos (48.2\%), seguido del grupo de 18 a 25 años, el cual aparecía un $40.9 \%$.

Lo anterior significa que casi 9 de cada 10 mujeres que se proyectan en los anuncios publicitarios de las revistas femeninas mantienen una apariencia juvenil, la cual ronda de entre los 18 a los 35 años de edad. Esto es, en este tipo de publicaciones suele destacarse la presentación de las mujeres jóvenes. El resto de las mujeres, esto es aquellas de más de 36 años representaron el 7.5\% y un $2 \%$ de mujeres con una apariencia menor a $\operatorname{los} 18$ años. 
La etnicidad o color de piel de la mujer que muestran los personajes principales de los estudios fue el siguiente paso. El objetivo por el cual se incluyó ésta fue para conocer en qué medida se destacan las características físicas de la mujer. Al respecto, los resultados indican que en poco más de dos de cada tres $(67.4 \%)$ anuncios las mujeres tenían rasgos caucásicos, seguidas de quienes presentan rasgos latinos de piel morena clara $(29.8 \%)$. El resto de las mujeres que participan de este tipo de mensajes son las de raza negra $(2.2 \%)$, asiáticas $(0.5 \%)$ y latinas de piel morena oscura $(0.2 \%)$. Hay que considerar que las revistas son destinadas al público mexicano y se pensaría que las imágenes presentadas representarían al público al que se dirige.

El color de cabello que identificaba a las mujeres de los anuncios fue el color café con 47\% ( $\mathrm{n}=621)$, luego personajes de cabello rubio con $39 \%$, y en tercero lugar protagonistas de cabello negro con 8.9\%, dejando sólo un 4.2\% para el cabello pelirrojo y 1\% para otros tonos menos convencionales como el azul y rosa.

La complexión que identifica a las mujeres en los anuncios indica que más de la mitad de ellas presenta una complexión regular, seguido de quienes participan de complexión delgada (43.1\%). La diferencia entre estas dos categorías reside en que "delgada" toma como referencia si aparece muy marcada la clavícula o huesos y piernas y brazos de un tamaño pequeño.

La complexión atlética se presentó en $1.7 \%$ de los casos, se tomaba en cuenta cuando se mostraba definición muscular, brazos/piernas o abdomen marcado. Solo se presentaron cuatro casos $(0.6 \%)$ donde la complexión de la mujer era de sobrepeso/obesidad.

La manera en la que los anunciantes presentan a las mujeres en sus campañas publicitarias también es de importancia. En general se encontró que en un tercio de éstas (68.8\%) se mostraba a la mujer de cuerpo completo, esta categoría también incluye cuando el corte de la imagen se da debajo de la cadera. En una cuarta parte $(27.1 \%)$ se mostraba un acercamiento del rostro y un $2.3 \%$ de los casos incluía solo la imagen de las piernas de una mujer. $\mathrm{Y}$ en un $0.9 \%$, es decir, seis casos se mostró un cuerpo sin rostro al igual que una imagen de solo las manos.

En la mayor parte de los casos (96.3\%) no se presentó ni se hizo alusión a la desnudez de la modelo en el anuncio.

Las seis revistas analizadas pueden ser divididas en dos grupos, en el primero se ubicaría a las que se dirigen a mujeres de hasta 34 años y en el segundo caso, a las que se dirigen a las mujeres de más de 34 años. Se destaca que las revistas enfocadas en mujeres de hasta 34 años presentaban persona- 
jes con una apariencia de 18-25 años de edad en un $46.7 \%$ seguido de 26-35 años con $43.5 \% \quad(n=306)$, mientras que las revistas enfocadas en mujeres de más de 35 años presentan personajes con apariencia de 2635 en más de la mitad de los casos $(52.5 \%$ $n=335$ ), seguido de $18-25$ en un $35.5 \%$. A pesar de que un grupo de revistas se enfoca a mujeres de más de 35, la representación de mujeres con apariencia de más de 35 años solo se presenta en el $8.7 \%$ de sus casos.

Las dos categorías de anuncios más encontradas fueron moda y cuidado personal, si se observa específicamente que características presentan en las mujeres de sus anuncios se encuentra que la categoría de anuncios de moda presenta en un $78.5 \%$ de sus casos ( $n=368)$ a una sola mujer. La mujer presente en estos anuncios aparenta una edad de $18-25$ en un $47.3 \%$ de los anuncios $(\mathrm{n}=357)$, se identifica con rasgos caucásicos en casi un 68\% de las ocasiones, seguido de latina con piel morena clara en un $28.4 \%$ ( $n=363)$ y aparece con cabello color café en el 43.8\% (n=354). Más de la mitad $(55.7 \%$ $\mathrm{n}=355)$ de los personajes tienen una complexión regular y se muestran de cuerpo entero en el $84.5 \%$ de los anuncios de la categoría. Se presentaron nueve anuncios en los que se hacía alusión a la desnudez.

Por otra parte, las mujeres presentadas en los anuncios de productos de cuidado personal aparentaban una edad de 26-35 en casi un 46\% ( $\mathrm{n}=218)$. Los rasgos o la etnicidad más visible en esta categoría es la caucásica con $69 \%$, en segundo lugar, se encuentra la latina con piel morena clara con $29 \%$ $(\mathrm{n}=214)$. El cabello es café en casi el 50\% de los anuncios $(n=200)$. La complexión del personaje es regular en más del $50 \%$, seguido de un $46 \%$ de complexión delgada. Más de la mitad de los anuncios presentaban al personaje de cuerpo entero, otro $42 \%$ $(n=221)$ mostraba solo el rostro. Se presentaron 13 anuncios en la categoría de producto en los cuales se hacía alusión a la desnudez.

\section{DISCUSIÓN}

De acuerdo con Wolf (1991) el sentido de la belleza no es universal ni inmutable, aunque en la parte occidental del mundo se pretenda que los ideales de belleza provienen de un modelo platónico de mujer ideal. En este aspecto es en donde la publicidad juega un papel muy destacado, ya que sobre todo en las revistas de estilo de vida y moda se presentan imágenes de belleza idealizada que usualmente suelen favorecer cierto tipo de características, las cuales finalmente podrían ser consideradas como punto de referencia. Gracias a los medios masivos de comunicación, los individuos pueden compararse con sujetos lejanos, como las celebridades o modelos que ahí aparecen y en muchas ocasiones han sido alterados digitalmente sin dar 
un aviso previo sobre las modificaciones realizadas.

Existe una relación muy estrecha entre los anuncios y el contenido editorial de las revistas (Kilbourne, 2000), por lo tanto, las imágenes idealizadas y las características representativas de la belleza no son exclusivas de los anuncios, sino que también pueden permearse en el contenido editorial. Morry y Staska (2001), concluyen que la exposición a las revistas se asocia con la internalización del ideal de delgadez en las mujeres y que aquellas que están en mayor contacto con revistas de belleza tienden a tener una preocupación mayor sobre su apariencia física y pueden mostrar comportamientos alimenticios más desordenados que las que no tienen contacto con estos medios.

Casi todas las imágenes de las mujeres que se proyectan en la publicidad, contribuyen a preservar el orden existente, mostrando rasgos y condiciones difíciles de alcanzar y proporcionando soluciones para intentar acercarse a ellos, pudiendo generar inseguridad o insatisfacción con las características propias. La publicidad exige economía de la comunicación, esto es que en un espacio o tiempo corto deben dar a entender su mensaje, los publicistas lo logran mediante la perpetuación de estereotipos tradicionales de clase, raza y sexo, ya que, al ser conocidos, el lector no tarda en identificarlos. Al ser un recurso recurrente, el problema surge cuan- do estos estereotipos se tornan normales, estableciendo y moldeando la percepción de lo que es normal y lo que es un defecto en el cuerpo (Bordo, 2004).

El estudio basado en el análisis de contenido realizado a la publicidad que se difunde a través de las revistas femeninas, en donde se buscó identificar las características físicas con las que relacionan a los personajes femeninos que participan de los anuncios publicitarios, encontró que en ellos prolifera la participación de mujeres con un rango de edad que va de los 18 a los 35 años. Este segmento de edad representó el 89\% de los casos en donde aparecieron mujeres, con lo cual se hace un énfasis en la juventud de los personajes. Ellos mismos establecen que ese es el rango perfecto/deseable de edad, sin embargo, no hay que preocuparse, ya que en tanto la persona se alejan de esa edad, le pueden ayudar con los productos que ellos mismos proporcionan, así al menos podrás aparentar pertenecer al rango de edad ideal.

Los resultados señalados representan una diferencia sustancial por ejemplo a los que encontraron Cáceres Zapatero y Díaz Soloaga (2008), quienes en su estudio destacaron la presencia de un $9.5 \%$ de personajes con un aspecto aniñado dada la tendencia de la publicidad de infantilizar a la mujer a través del peinado, vestimenta, adornos o actitud, en este estudio presentaron muy po-cos casos en los que el personaje aparentaba una 
edad menor a los 18 años y no se presentaron casos de infantilización de los personajes de mayor edad. Puede pensarse que los grupos de edad mostrados van de acuerdo con los grupos de edad meta que las revistas mencionan en sus kits de medios.

Sin embargo, los resultados sí concuerdan con los trabajos de Fredrickson y Roberts (1997), Cortese (2008), Plakoyiannaki y Zotos (2008), quienes destacan en sus conclusiones la predominancia de la juventud en las representaciones. Lo más destacado es que aún en aquellas revistas en las que sus lectoras meta tienen hasta 45-54 años de edad, no se veían mujeres de esas edades reflejadas en un porcentaje significativo en los anuncios presentes en las mismas. La explicación que se ha generado al respecto refiere sobre todo al hecho de relacionar a la vejez con la pérdida de la belleza. De acuerdo a Benbow-Buitenhuis (2014) el envejecimiento femenino y la degradación de la belleza se ve como una pérdida social, ya que el individuo se ve cada vez más lejano del ideal de belleza juvenil. Esto significa que, al pasar por el proceso natural de envejecimiento, con lo que eso conlleva en la apariencia física (aparición de arrugas, manchas, cambio en la elasticidad de la piel, canas, entre otros), la mujer, quien muchas veces es juzgada u observada desde el punto de vista meramente físico, pierde su lugar y es relegada por otras mujeres que se encuentren en el rango de edad deseable. En este caso, es importante destacar cómo es que las revistas femeninas contribuyen a presentar su ideal de belleza, de ahí que la propuesta se encamina a mantenerla, o desaparecer, tal y como simbólicamente se realiza mediante la acción de no considerar a un segmento que supere la edad que ellos mismos han establecido. Sin embargo, así como ellos ponen las condiciones de belleza de acuerdo a la edad, también son capaces de presentar las soluciones con base en las cuales se pudiera poner un remedio a este tipo de situaciones. Las cremas y los insumos que te ofertan son parte de ello.

Al igual que la edad de las mujeres, en los anuncios también se deja en claro la propuesta de color de piel considerada como parte del modelo a seguir. Más de la mitad de los casos en donde se presentó a las mujeres en los anuncios publicitarios tenían rasgos caucásicos o color de piel blanca, o en su caso, se trataba de mujeres con rasgos latinos con piel morena clara. En este sentido se coincide con el trabajo realizado por parte de Cáceres Zapatero y Díaz Soloaga (2008), quienes mencionaron que el perfil estético de la mujer ideal según los anuncios españoles incluye ser una mujer blanca. También Yin y Pryor (2012) referían que se percibe que las mujeres atractivas tienen un color de piel más claro que las mujeres no atractivas. 
Es importante destacar que aun y cuando las revistas analizadas son para el público mexicano y se esperaría que su contenido, incluyendo el de sus anuncios, represente al público al que se dirige, es cuestionable que no se presenten mujeres con rasgos latinos con piel más oscura. Sin embargo, no todas las marcas de los anuncios son de compañías mexicanas y en ocasiones la misma campaña publicitaria podría ser utilizada en diferentes países, lo que llevaría a cuestionar la falta de presencia de mujeres negras o asiáticas en los anuncios como muestra del ideal de belleza globalizado. Los medios se han convertido en el elemento más importante para lograr una homogenización de los estándares de belleza, incluso en diferentes partes del mundo. Si los anuncios, las revistas y los medios apuntan a las mismas características femeninas todo el tiempo, establecen esos rasgos como los deseables o incluso los comunes.

Encontramos entonces a una mujer joven y blanca, pero también en los anuncios publicitarios se pretende imponer como un ideal de belleza a las personas, en este caso a las mujeres de acuerdo a su complexión física. Yin y Pryor (2012) mencionan que tanto en las culturas occidentales como orientales se ha remarcado la delgadez como un ideal de belleza en las representaciones de los medios. De igual manera Cáceres Zapatero y Díaz Soloaga (2008) incluyen el ser delgada como una característica del perfil estético ideal. En el presente estudio se encontró que más de la mitad de los personajes femeninos analizados presentaba una complexión regular y después una gran mayoría presentaba una complexión delgada. La diferencia entre las dos categorías es que "delgada" toma como referencia si aparece muy marcada la clavícula o huesos, y piernas y brazos de un tamaño pequeño.

También se buscó como se presentaba la imagen de la mujer en los anuncios publicitarios, es decir que partes del cuerpo eran visibles en el anuncio. Se coincide con Cáceres Zapatero y Díaz Soloaga (2008) en que en su mayoría se presentaba a la mujer de cuerpo completo sin embargo se difiere en que la segunda presentación más común es el busto. En este estudio se encontró en segundo lugar el acercamiento al rostro. Sin embargo, sí se presentaron algunos casos donde se fragmentaba el cuerpo femenino, en algunos solo aparecían las piernas de la mujer y en seis casos particulares se mostró una parte del cuerpo pero sin rostro. Esto alude a lo mencionado por Patterson, O’Malley y Story (2009) sobre la industria publicitaria y la cosificación del cuerpo femenino, donde se presenta como símbolo de un objeto, como un objeto fragmentado hecho de partes sin un total, como un objeto para ser visto o como un objeto a ser usado. Los casos presentados en los que se enfoca a 
una sola parte del cuerpo como piernas o manos quizá buscan amplificar la imagen para mostrar un producto como zapatos o un color de esmalte de uñas, sin embargo, los anuncios en los que se muestra el cuerpo y se elimina la cabeza despersonaliza al personaje y lo deja como un objeto fragmentado como lo establecen los autores previamente mencionados.

Se concluye que los anuncios publicitarios enfocados a los productos de belleza y cuidado personal siguen mostrando una representación de la mujer con los rasgos identificados por otros autores como participes en el estereotipo de belleza ideal feme- nina como color de piel blanca, complexión delgada, entre otros.

Incluso cuando las revistas en las que se muestran los anuncios van dirigidas a mujeres de grupos de edad más avanzados, no se representan mujeres de esos grupos de edad, haciendo un énfasis especial en la cuestión de edad.

Los hallazgos de esta investigación apuntan a centrar la atención en la característica de edad que se presenta tanto en la representación de las mujeres en la publicidad, como en la oferta de productos y mensajes relacionados a la edad. 


\section{FUENTES CONSULTADAS}

Benbow-Buitenhuis, A. (2014). "A feminine double-bind? Towards understanding the commercialization of beauty through examining anti-ageing culture". En: Social Alternatives 33(2), 4349.

Berger, A. A. (2011). Ads, fads, and consumer culture: advertising's impact on American character and society. Lanham: Rowman \& Littlefield.

Bordo, S. (2004). Unbearable weight: feminism, western culture, and the body. University of California Press.

Cáceres, M. y Díaz, P. (2008). "La representación del cuerpo de la mujer en la publicidad de revistas femeninas". En: Estudios sobre el Mensaje Periodístico 14, 309-326.

Centro Nacional de Equidad de Género y Salud Reproductiva. (2004). "Guía de Trastornos Alimenticios" [PDF]. Secretaría de Salud.

Cortese, A. (2008). Provacateur: images of women and minorities in advertising. (3 ed.). Maryland: Roman \& Littlefield Publishers, Inc.

Fredrickson, B.L. y Roberts, T.A. (1997). "Objectification theory: toward understanding women's lived experiences and mental health risks". En: Psychology of Women Quarterly 21(2), 173206.

Goffman, E. (1987). Gender advertisements: Erving Goffman (introduction by Vivian Gornick). Nueva York: Harper \& Row.

Kilbourne, J. (2000). Can't buy my love, how advertising changes the way we think and feel. (1era. ed.). Nueva York: Free Press.

Muise, A. y Desmarais, S. (2010). "Women's perceptions and use of 'anti-aging' products". En: Sex Roles 63, 126-137.

Morry, M. M. y Staska, S. L. (2001). "Magazine exposure: internalization, self-objectification, eating attitudes, and body satisfaction in male and female university students". Journal of Bebavioural Science 33(4), 269-279.

Odekerken-Schröder, G., De Wulf, K. y Hofstee, N. (2002). "Is gender stereotyping in advertising more prevalent in masculine countries?: a cross-national analysis", En: International Marketing Review 19(4), 408-419.

Patterson, M., O'Malley, L., y Story, V. (2009). "Women in advertising: representations, repercussions, responses”. En: Irish Marketing Review, 20 (1), 9-22. 
Plakoyiannaki, E., y Zotos, Y. (2008). "Female role stereotypes in print advertising”. En: European Journal of Marketing, 43(11/12), 1411-1434.

Qualter, T.H. (1994). Publicidad y democracia en la sociedad de masas. Barcelona: Paidós Comunicación.

Stephens, D.L., Hill, RP. y Hanson, C. (1994). "The beauty myth and female consumers: the controversial role of advertising". En: Journal of Consumer Affairs 28(1), 137-153.

Wolf, N. (1991). The beauty myth: how images of beauty are used against women. Harper Co-llins.

Yin, B. y Pryor, S. (2012). "Beauty in the age of marketing". En: Review of Business \& Finance Case Studies 3(1), 119-132. 